\title{
Island Coastline Change Detection Based on Image Processing and Remote Sensing
}

\author{
Maged Bouchahma ${ }^{1}$, Wanglin Yan $^{1} \&$ Mohamed Ouessar ${ }^{2}$ \\ ${ }^{1}$ Yan Lab, Graduate school of media and governance, SFC Keio University, Fujisawa-shi, kanagawa-ken, Japan \\ ${ }^{2}$ Mohamed Ouessar: Institut des Régions Arides (IRA), 4119 - Médenine, Tunisia \\ Correspondence: Maged Bouchahma, Yan Lab, Graduate school of media and governance, SFC Keio University, \\ 5322 Endo, Fujisawa-shi, kanagawa-ken, Japan. Tel: 81-466-493-623. E-mail: boumaged@sfc.keio.ac.jp
}

Received: January 4, 2012 Accepted: February 14, 2012 Online Published: May 1, 2012

doi:10.5539/cis.v5n3p27

URL: http://dx.doi.org/10.5539/cis.v5n3p27

\begin{abstract}
As an island ecosystem, Djerba, a region of Tunisia located on the southern shore of the Mediterranean Sea, is characterized by limited natural resources and threatened by land degradation due to rapid socio-economic development and heavy human-induced changes to the landscape. The objective of this study is to build a system based on computer vision and remote sensing data for monitoring changes in the coastal zones of an island. We employed monthly Landsat Thematic Mapper (TM) satellite images of the study area ranging from 1984 to 2009. The images were preprocessed using the Speeded Up Robust Features (SURF) algorithm to superimpose remote sensing images at exactly the same coordinates. We then used two comparison techniques to auto-validate the detection of changes. The first technique is based on a window-to-window comparison of the coastal zones and the second technique compares shoreline changes using edge detection. Three highly affected regions were identified. The Bin El-Ouidiane (in the southeast) and Rass Errmal (in the north) regions underwent deposition during the study period, whereas the region of Rass El Kastil (in the north) underwent high erosion.
\end{abstract}

Keywords: coastal line change, SURF, canny edge detector, djerba, landsat TM

\section{Introduction}

Mediterranean coastal zones are under great pressure from both human intervention and natural processes (marine current, waves, tides, etc.). As a result, nearly half of the region's coastal zones have changed markedly during the last two decades (Ravaioli et al., 2009; Bethoux \& Gentili, 1996). During this time period, Djerba Island, one of Tunisia's premier destinations for European tourism, has seen a rapid development of tourist facilities and an increase in the population of the coastal zones, causing several coastal problems. Policies and action plans are urgently required to prevent the deterioration of coastal ecosystems and to realize a sustainable development of the resources on the island.

Previous studies have examined coastal changes in the Mediterranean. Ricchetti et al. (2004) studied the coastal areas of the Salento Peninsula (southern Italy) which was suffering from erosion along its coasts; more recently, Ravaioli et al. (2009) presented an observation system for Italian coastal zones. Ahlin and Niemeyer (2009) studied the coastal monitoring of Gaza using remote sensing and a geographic information system (GIS), detailing the processes of sedimentation and erosion around the region. Shalaby and Tateishi (2006) used remote sensing and GIS for mapping and monitoring land cover and land-use changes in the north western coastal zone of Egypt. As for previous studies on the coastal zone around our study area, we refer to the national report carried out by the Tunisian Ministry of Environment and Territory Planning,, which presents statistics and general information about coastal changes in all Tunisian territories. This report classifies the coastal zones of Djerba as one of the most affected coasts in Tunisia. In terms of academic studies, Sammari et al. (2006) considered sea level variability and tidal resonance in the Gulf of Gabes. Based on measurements carried out between 1999 and 2003, this study demonstrates that tidal changes can reach $1 \mathrm{~m}$. Masmoudi et al. (2005) studied the evolution and morphodynamics of the barrier island system south east of Djerba. All the previous studies mentioned that changes have taken place around the coastal zones of Djerba, but no specific and precise information about the most affected regions and the degree of change have been given. Therefore, a study of the changes to the coastal landscape in recent decades is required to determine the most affected regions and to clarify the dynamics of these changes through a historical view of the island. 
The previous studies are usually based on the functionality offered by a particular GIS system. Also, the pre-processing operations - especially the extraction of coastlines from the satellite images - are generally performed manually by experts using interpretation techniques. The aim of this study is to develop a methodology to automatically monitor an island's coastline based on computer vision techniques and remote sensing data. Using Landsat Thematic Mapper (TM) data, threshold binarization, Canny edge detector and SURF algorithm we detected changes around the island and determined the most affected regions of Djerba. We were therefore able to approximately measure the changes in these regions and thus provide useful information for decision makers.

\section{Study Area}

The island of Djerba is located in the south part of the republic of Tunisia $\left(33^{\circ} 47^{\prime} 0^{\prime \prime} \mathrm{N}, 10^{\circ} 53^{\prime} 0^{\prime \prime} \mathrm{E}-\mathrm{WGS} 84\right.$ coordinates) (Figure 1). As a small island with an area of $514 \mathrm{~km}^{2}$, Djerba is characterized by limited resources. The economy of the island is based on tourism (more than 100 hotels, tens of restaurants, a casino, spa, and so on) and artisanal commerce. The majority of its population of 120,000 is concentrated around the coastal zones, which has led to the overexploitation of its coastal resources. Djerba is connected to the mainland by a Roman road as shown in Figure 2. Halfway along this road, there is a bridge; the bridge was $13.5 \mathrm{~m}$ long until 2007, when it was extended to $160 \mathrm{~m}$ in order to improve the circulation of sea water around the island.
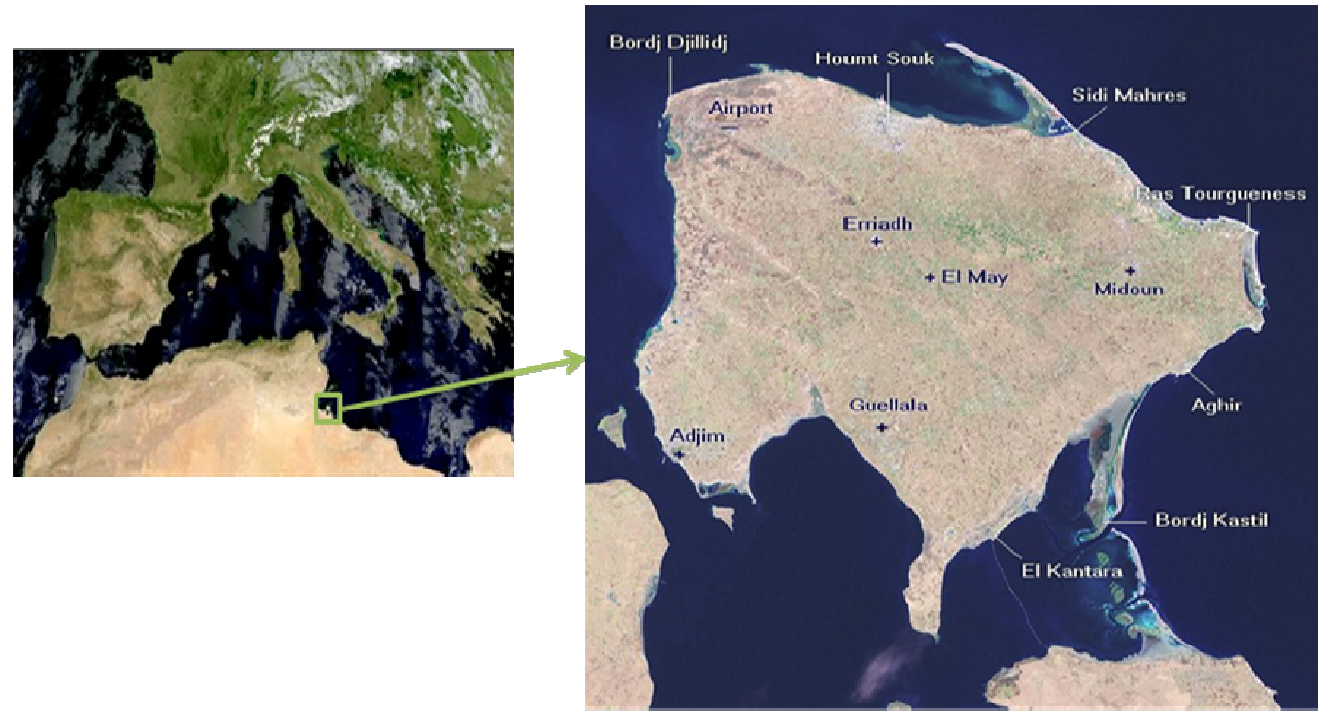

Figure 1. The island of Djerba
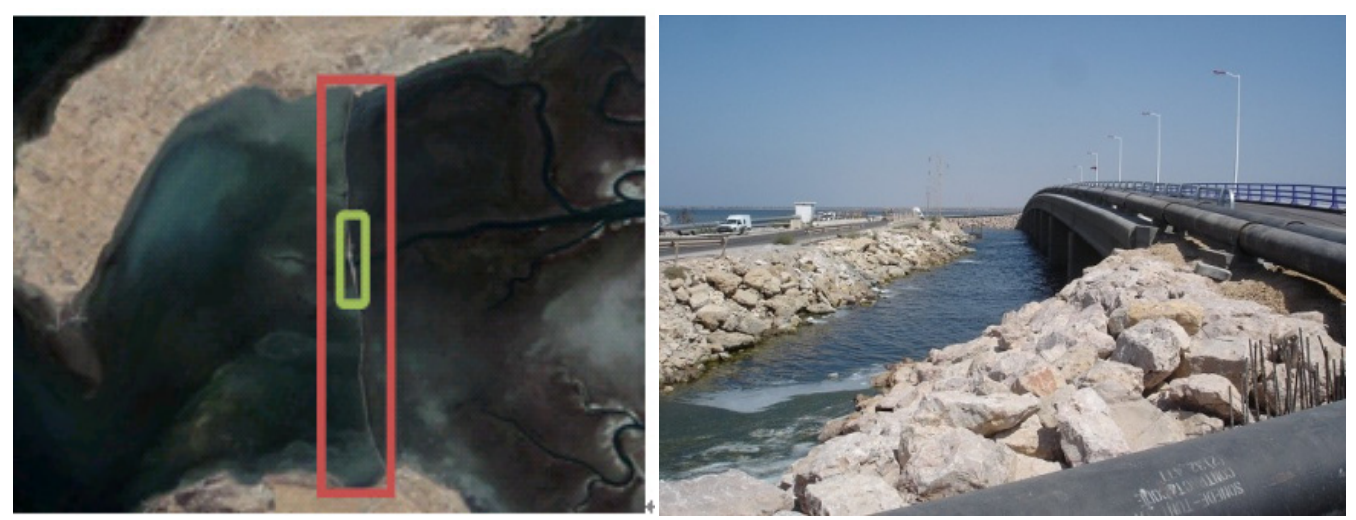

Figure 2. The bridge in the middle of the Roman road 
The waterway underneath this bridge is the only connecting point between the Gulf of Boughrara and the eastern part of the island. Near this bridge are the barrier islands, studied by Masmoudi et al. (2005), which are considered to be one of the most affected parts of the island. The ecosystem around this part of the island has changed dramatically. As the majority of the population of Djerba lives within the coastal zones, it is necessary to appreciate the effects of agricultural, industrial, and other human activities on coastal habitats and water quality, as well as to understand the impact of these changes on ecological dynamics, ecosystem health, and biological diversity. The objective of this research is to build on existing long term data that is critical to the understanding of future short-term changes in Djerba.

The intention is to determine - based on long-term trends ( 25 years) - where high rates of shoreline erosion and sedimentation may occur during the next few years and thus provide useful information to understand and to prevent the consequences of coastal changes on Djerba.

\section{Material}

As high resolution data is costly, uncommon, and often entirely unavailable for a long period for the study area, Landsat TM images were used as source material. These images were acquired between 1984 and 2009 (Table 1). Landsat 4 and 5 carry the TM sensors. The satellites orbit at an altitude of $705 \mathrm{~km}$ and provide a 16-day, 233 -orbit cycle with a swath overlap that varies from 7 percent at the Equator to nearly 84 percent at $81^{\circ}$ north or south in latitude. These satellites were designed and operated to collect data over a $185 \mathrm{~km}$ swath. The TM sensor primarily detects reflected radiation from the Earth's surface in the visible and near-infrared (NIR) wavelengths. The TM sensor has seven spectral bands. The wavelength range for the TM sensor is from the visible through the mid-IR and into the thermal-IR portion of the electromagnetic spectrum. The images were collected using the image viewer on the USGS site (http://glovis.usgs.gov/).

Table 1. Used images

\begin{tabular}{llll}
\hline Acquisition date & Satellite images & Resolution & Date Near \\
\hline 1984/06/18 09:17:56 & Landsat 5 TM & $30 \mathrm{~m}$ & Solstice \\
1984/09/22 09:19:42 & Landsat 5 TM & $30 \mathrm{~m}$ & Equinox \\
2009/09/27 09:39:29 & Landsat 5 TM & $30 \mathrm{~m}$ & Equinox \\
2009/06/23 09:38:03 & Landsat 5 TM & $30 \mathrm{~m}$ & Solstice \\
\hline
\end{tabular}

The tide depends mainly on the relative positions of the Moon, the Sun, and the Earth. The lowest tides of the year occur during the winter and summer solstices and the highest tides occur during equinoxes. A solstice is an astronomical event that happens twice each year when the Sun's apparent position in the sky reaches its northernmost or southernmost extreme. An equinox occurs twice a year, when the tilt of the Earth's axis is inclined neither away from nor toward the Sun, with the center of the Sun being in the same plane as the Earth's equator.

Table 2. Solstice and equinox dates

\begin{tabular}{lllll}
\hline Year & Vernal Equinox & $\begin{array}{l}\text { Northern } \\
\text { Solstice }\end{array}$ & $\begin{array}{l}\text { Autumnal } \\
\text { Equinox }\end{array}$ & $\begin{array}{l}\text { Southern } \\
\text { Solstice }\end{array}$ \\
\hline 1984 & $3 / 2010: 24$ & $6 / 215: 02$ & $9 / 2220: 33$ & $12 / 2116: 23$ \\
2006 & $3 / 2018: 25$ & $6 / 2112: 25$ & $9 / 234: 03$ & $12 / 220: 21$ \\
2007 & $3 / 210: 07$ & $6 / 2118: 05$ & $9 / 239: 50$ & $12 / 226: 07$ \\
2008 & $3 / 205: 48$ & $6 / 2023: 59$ & $9 / 2215: 44$ & $12 / 2112: 03$ \\
2009 & $3 / 2011: 43$ & $6 / 215: 45$ & $9 / 2221: 18$ & $12 / 2117: 46$ \\
2010 & $3 / 2017: 31$ & $6 / 2111: 28$ & $9 / 233: 09$ & $12 / 2123: 38$ \\
\hline
\end{tabular}

To perform better comparisons, we selected images acquired near solstice and equinox dates (Table 2), thereby avoiding differences in the tide level. After checking the list of available images, we chose the list given in Table 1. The earliest images available were taken as the baseline reference (18/06/1984). 
The graphs in Figure 3 present the tides at Djerba Hawmet Essouk station for the selected image dates. These graphs were generated using WXTide32 software, which predicts tides from 1970 until 2037 around the world. In these graphs, we can suppose that the tide levels can be ignored because the difference between the reference date tides (1984) and the most recent tides (2009) are around $0.3 \mathrm{~m}$. These differences are too small to be detected in the TM images, which have a resolution of $30 \mathrm{~m}$.
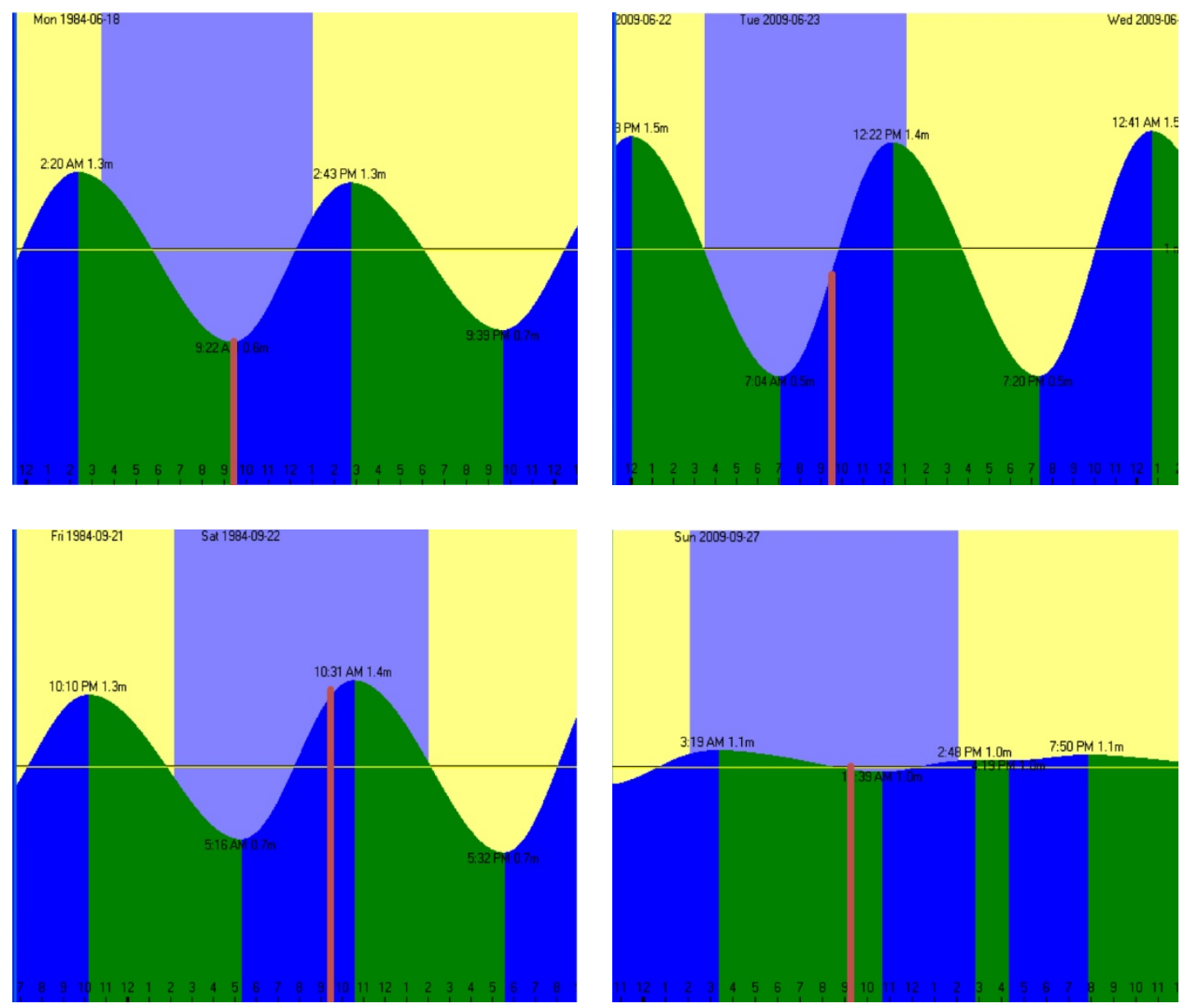

Figure 3. Tides approximation for image set using WXTide32 software

\section{Methodology}

We followed a three step methodology to detect changes in the coastline (Figure 4). The first step was a preprocessing step where we used the SURF algorithm to extract the study area from satellite images. Then, change detection was carried out using two different techniques: window-to-window comparison and shoreline change detection. After validating the changes reported by the two techniques, we classified individual changes as being due to either erosion or sedimentation.

We based our choice of bands for the best detection of the coastline on the work of P. S. Frazier and K. J. Page (2000). It demonstrates that Band 5 gives better separation between the land and sea and results in the best detection of the coastline. Band 5 wavelengths are between 1.55 and $1.75 \mu \mathrm{m}$ (near-infrared).

\subsection{Preprocessing}

To optimize the processing time of the change detection algorithm, we manually cropped a sub-image containing only the study area from the image acquired on 1984/06/18. As the sensor acquires the images in 16-day cycles, the acquiring position can be slightly different from one date to another. To avoid this problem, we automated the referencing and the cropping of the study area in different images using the Speeded Up Robust Features (SURF) algorithm applied on the reference image. SURF is a robust image detector and descriptor, first presented by Herbert Bay et al. in 2006, that can be used in computer vision tasks like object recognition or 3D reconstruction. 


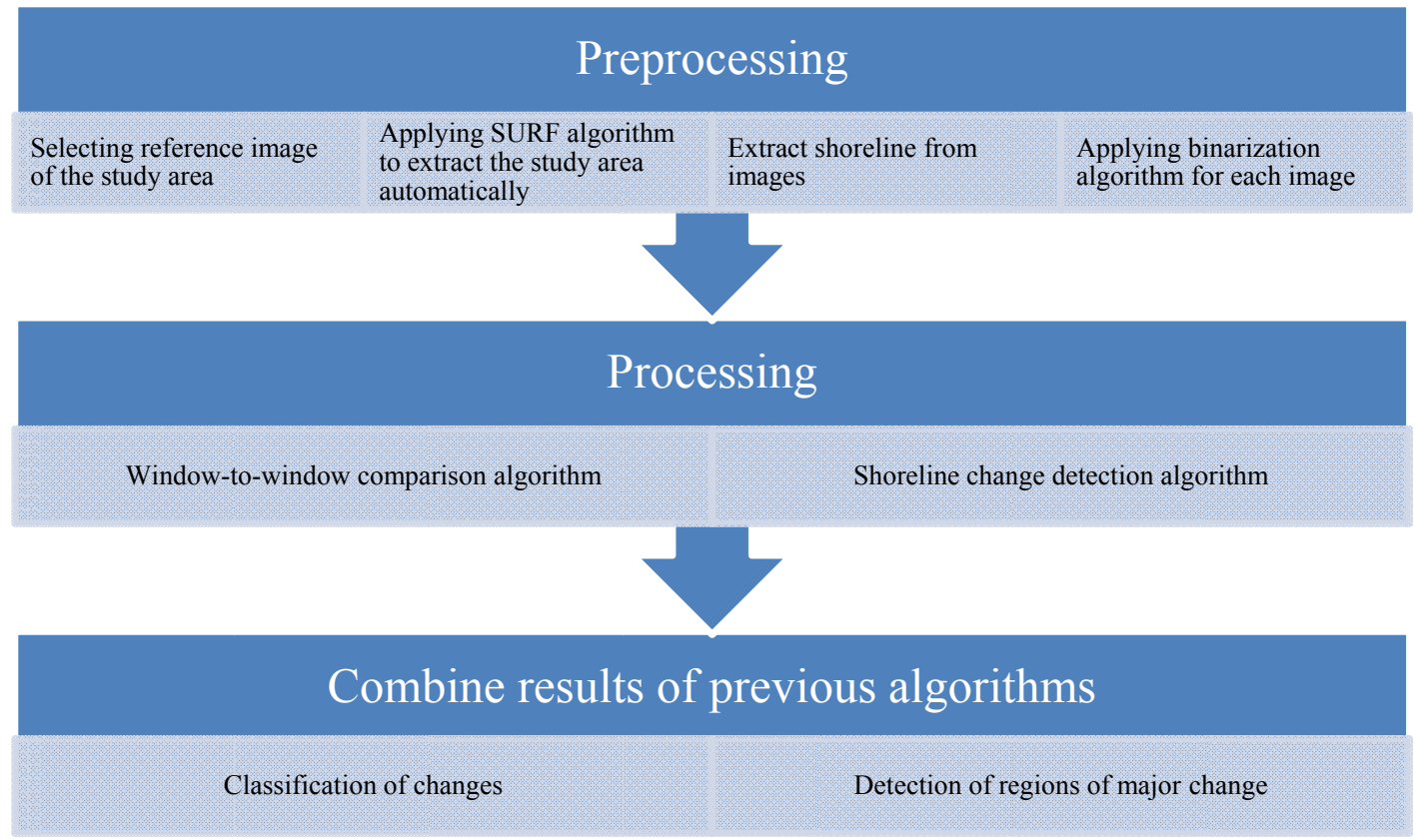

Figure 4. Methodology

It is partly inspired by the scale-invariant feature transform (SIFT) descriptor. The standard version of SURF is several times faster than SIFT and is claimed by its authors to be more robust against different image transformations than SIFT. For basic image features, it uses a Haar wavelet approximation of the determinant of a Hessian blob detector. SURF is invariant against scale, translation and rotation, luminosity, and color.

A threshold binarization was used to separate the land from the sea (Figure 5). The threshold is generated automatically based on the image histogram, the form of which is two dispersed Gaussian curves; the value of the binarization threshold is the mean of the histogram. To detect the coastline, we applied the Canny edge detector. The Canny operator was designed to be an optimal edge detector. It takes as input a grayscale image and produces as output an image showing the positions of tracked intensity discontinuities. The Canny operator works in a multi-stage process. First, the image is smoothed by Gaussian convolution. Then, a simple 2-D first derivative operator is applied to the smoothed image to highlight regions of the image with high first spatial derivatives. Edges give rise to ridges in the gradient magnitude image. The algorithm then tracks along the top of these ridges and sets to zero all pixels that are not actually on the ridge top so as to give a thin line in the output, a process known as non-maximal suppression.

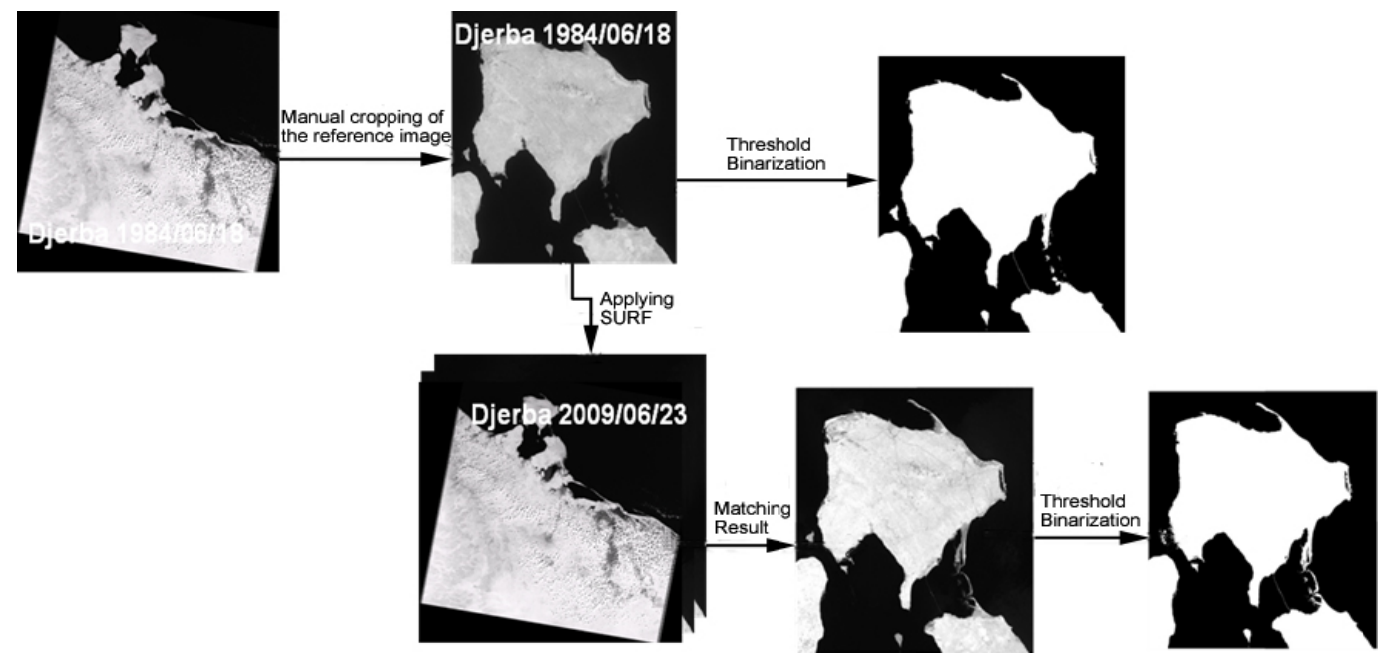

Figure 5. SURF algorithm 
We have chosen the application of the Canny algorithm on binary images because its edge detection is better than detection using grayscale images (Figure 6). The output edge from the grayscale image contains discontinuities, such that it cannot serve as a model of the coastline. These arise due to the difficulty in detecting changes near marsh areas.

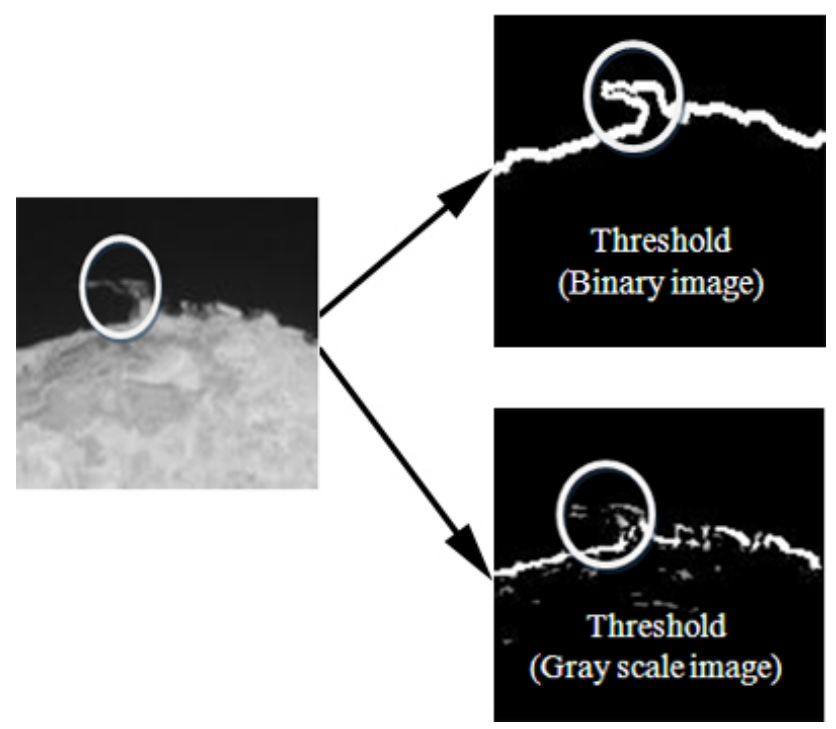

Figure 6. Coastline extraction

\subsection{Change Detection}

We combined two techniques to ensure superior detection of changes; we will refer to this method as shoreline changes by auto-validation. The first technique detects changes using window-to-window comparison of the binary image. The second uses shoreline changes based on edge detection. If the changes are confirmed in the two outputs of changes, we can then identify whether it is erosion or sedimentation using the window-to-window comparison technique.

We start by presenting the technique based on window comparison. It begins with the segmentation of the binary image of the study region into windows (Figure 7 and Figure 8). Then, to optimize the processing time, we select windows using edge images. A window is selected if using this technique, a window with the same coordinate as in the binary image contains an edge, meaning that it must contain a coastal zone. We compared the image acquired on $1984 / 06 / 18$ to the one acquired on $2009 / 06 / 23$ and the image acquired on 1984/09/22 to the one acquired on 2009/09/27.

This process is applied for all images. Each selected window of images from 2009 will be compared to the images' windows from 1984 (reference images).

The algorithm is described below:

Algorithm Detect_Changes_by_Region

For each window $\mathrm{w}$ in the image do

If $w$ contains an edge then

Add w to selected_windows.

End If

End For

For each window w in selected_windows

Compare the number of land pixels

Determine whether erosion or sedimentation occurred

End For

End Algorithm 

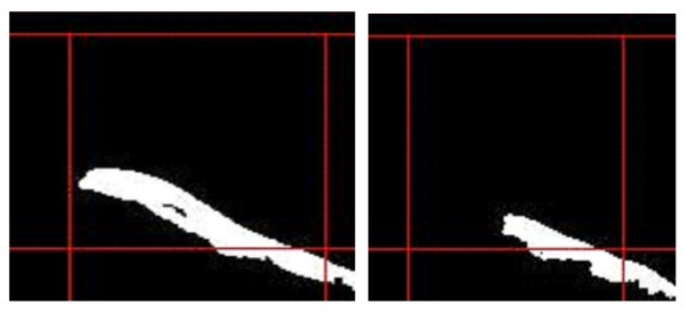

(a)

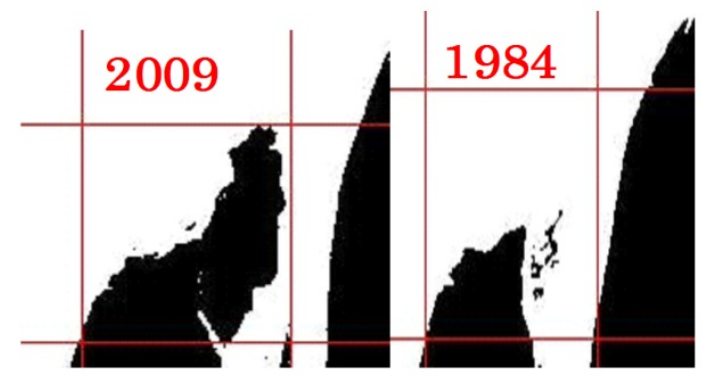

(b)

Figure 7. Comparison windows

(a) Case of deposition; (b) Case of erosion

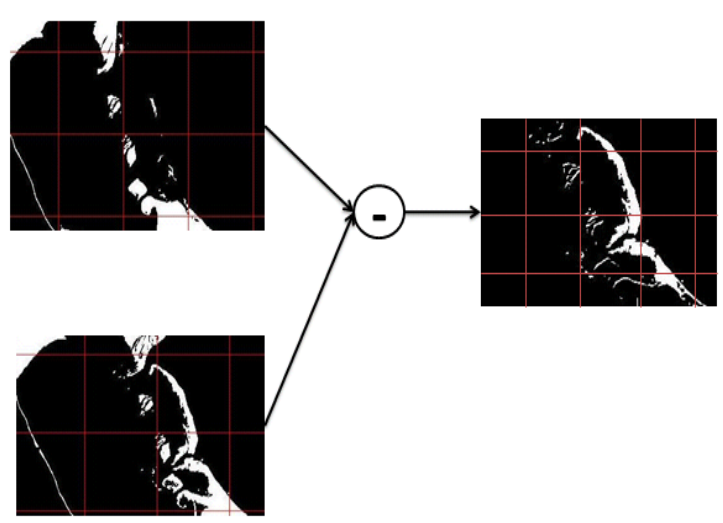

Figure 8. Bin-El ouidiane changes extraction

The second detection technique is based on shoreline changes. Thus, this technique was based on edge images. As the edge detection process does not give a 1-pixel line, we applied a process of simple skeletonization of the edge so that we were able to produce a 1-pixel shoreline. Here, we wish to emphasize that the images have the same sizes and references due to preprocessing using the SURF algorithm to crop our study region from the satellite images.

The rates of shoreline changes were calculated as follows:

- For each part of the island, we defined a local baseline of comparison. For the north coast of the island, we compared the coordinate of the shoreline pixels proportional to the first horizontal line of the image. For the south coast, the baseline was the image's last horizontal line. For the west coast, it was the image's first vertical line and for the east coast, it was the image's last vertical line.

- The transects were spaced at $600 \mathrm{~m}$ intervals both horizontally and vertically. Every coast transect was perpendicular to the corresponding baseline of the shoreline.

- These processes were applied to all the images and in the same manner.

- We compared the image acquired on 1984/06/18 to the one acquired on 2009/06/23 and the image acquired on $1984 / 09 / 22$ to the one acquired on 2009/09/27. 
- We calculated the distance of the shoreline pixel in intersection with the transect from the baseline as follows:

$>$ In the case of a horizontal baseline, take the absolute value of the difference between the $Y$ coordinate of the shoreline pixel $I(X, Y)$ and the $Y^{\prime}$ coordinate of the baseline pixel $B\left(X^{\prime}, Y^{\prime}\right)$ in intersection with the same transect: Dist $=\left|Y-Y^{\prime}\right|$.

$>$ In the case of a vertical baseline, take the absolute value of the difference between the $\mathrm{X}$ coordinate of the shoreline pixel $\mathrm{I}(\mathrm{X}, \mathrm{Y})$ and the $\mathrm{X}^{\prime}$ coordinate of the baseline pixel $\mathrm{B}\left(\mathrm{X}^{\prime}, \mathrm{Y}^{\prime}\right)$ in intersection with the same transect: Dist $=\left|\mathrm{X}-\mathrm{X}^{\prime}\right|$.

- To calculate the change between two dates, we only have to calculate the difference between the distances of the shoreline pixel in the same transect.

Figure 9, 10, 11 and 12 present the results from applying this algorithm to the image from 1986/06/18 compared to the image from 2009/06/23 and the image from 1986/09/22 compared to the image from 2009/09/27. This provides general trends in the shoreline changes during these periods.

\section{Results and Discussion}

The results indicate that the rate of change varies along the coastline. However, the western coastline exhibits in general a negative rate of change along the coastline. Meanwhile, the south, north, and east coasts of Djerba showed positive rates of change, but there is an extremely negative rate around the "Sabkha of Aghir" near "El Kantara". Based on the results from the two techniques, three regions were considered to be highly changed regions: Bin El-Ouidiane, Rass Errmal, and Rass El-Kastil.

\subsection{Bin El-Ouidiane}

The barrier island system studied by Masmoudi et al. (2005) was detected using our algorithms; it reveals several recent sand bodies that show an extraordinary and quick evolution (See Figure 8). This process has influenced the ecosystem of the Gulf of Boughrara (Sammari et al., 2005).

\subsection{Rass Errmal}

The remarkable positive rate of change in the north side of the island shown in Figure 9 reflects deposition on "Rass Errmal". The same change was detected using the comparison technique (See Figure 7(a)). Based on the results of the second techniques, the extension in Rass Errmal between 1984 and 2009 was found to be around $500 \mathrm{~m}$.

\subsection{Rass El-Kastil}

Figure 7(b) shows a barrier island system that developed near this area. The remarkable positive rate of change in the north side occurred around "Rass El-Kastil" (Figure 10).

In our method, we used Landsat TM which provides medium spatial resolution data at 16-day intervals over a long archival history, exceeding 25 years in most locations. The long archive period and repetitive capture makes the data useful for mapping bodies of water at a regional scale over a range of hydrological conditions and especially for island regions. Also, this method was based on two techniques to ensure the detection of changes from two perspectives. The execution time using this method was reduced by choosing a technique that windowed the coastal zones based on the edge detection technique.

According to this study, the analysis of medium resolution satellite imagery can give an indication of coastal changes; however, precise spatial results cannot be expected. In future works, high resolution images will be used in the highly changed regions and will be combined with this study and data collected from on-the-ground observations to evaluate the rates of change by year. 


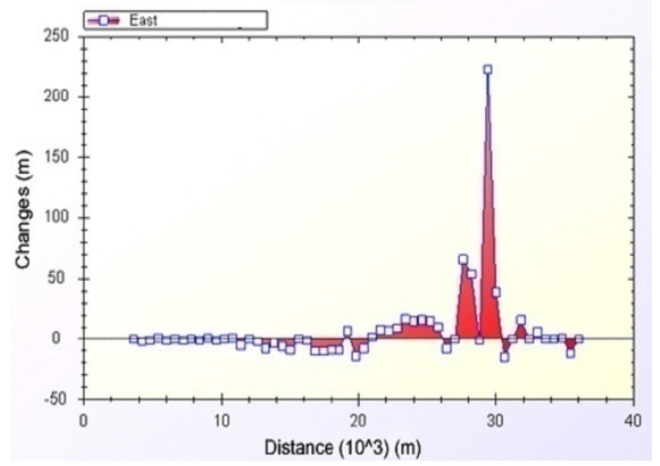

Figure 9. Djerba East coast changes

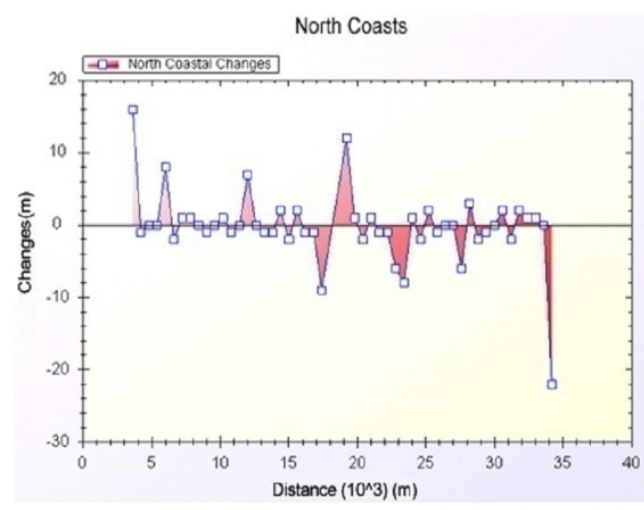

Figure 11. Djerba North coast changes

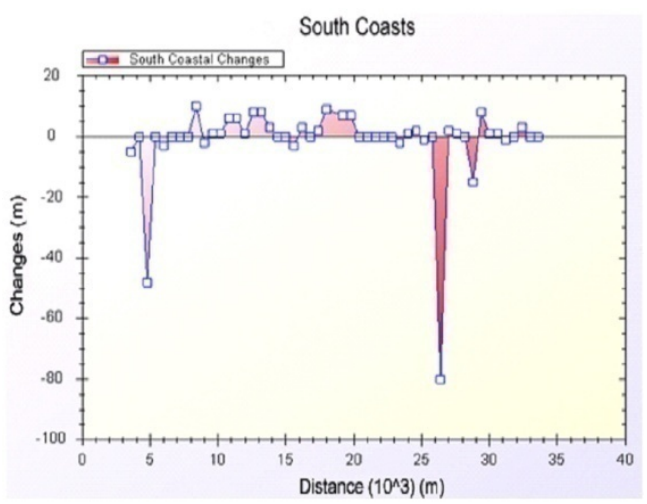

Figure 10. Djerba South coast changes

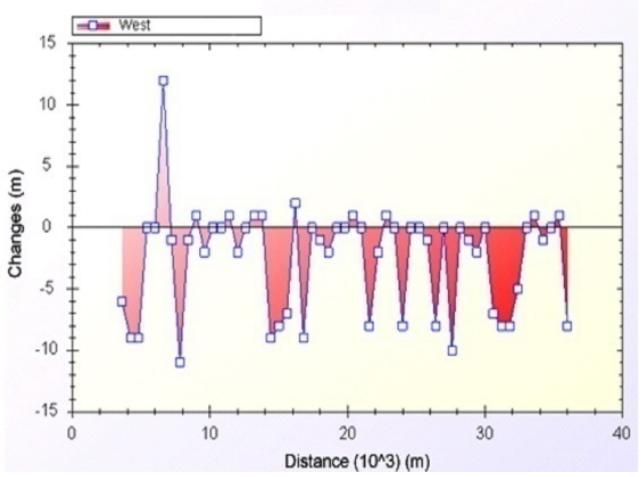

Figure 12. Djerba West coast changes

\section{Conclusion}

This work has focused on the development of an algorithm to detect the shoreline changes of an island using Landsat data. The method is based on two techniques to detect the changes and to auto-validate the changes for greater accuracy.

In general, a negative rate of change was calculated along the western coastline. However, the north, east, and south demonstrated positive rates of change, though there are also remarkable and important negative rates on these sides of the island. The added value of the developed methodology is that all the process of detection was automatic and occurred without any human intervention. As future work, data will be collected by field work to explain and to find the causes of the changes during the 25 year period. We will present a hypothesis to explain the cause of the changes in some regions; for example, the narrow opening of the bridge around "El Kantra" could be the primary contributor to the changes measured around the eastern and the south-eastern coasts. Future studies will be concentrated around the most affected regions (Rass Errmal, Bin El-Ouidiane and Rass El-Kestil) to develop a system to control the changes around these regions and to help decision makers determine what action is needed to decrease the variability of changes.

\section{Acknowledgements}

The work was supported by the MEXT Japanese Government scholarship.

\section{References}

Ahlin, K. A., \& Niemeyer, I. (2009). Coastal monitoring using remote sensing and geoinformation systems: estimation of erosion and accretion rates along Gaza coastline. 4th EARSeL Workshop Remote Sensing of the Coastal Zone.

Association pour la sauvegarde De l'île de Djerba. (2003). Agenda 21 Djerba, p. 154.

Burkhalter, S., Herold, N., \& Robinson, C. (2005). The coastal change analysis program: Mapping change and 
monitoring change trends in the coastal zone. International Workshop on the Analysis of Multi-Temporal Remote Sensing Images. http://dx.doi.org/10.1109/AMTRSI.2005.1469874

Elmzoughi, A., Zribi, M., \& Abdelfattah, R. (2008). Using long term NOAA-AVHRR NDVI time-series data for desertification monitoring in South Tunisia. In: Proceedings 3rd International Conference on Information and Communication Technologies: From Theory to Applications.

Tunisia. (1998). Ministry of environment and territory planning. National action program for combating desertification, p. 103.

Masmoudi, S., Yaich, C., \& Yamoun, M. (2005). Evolution and morphodynamics of barrier islands system in South East of Tunisia. Bulletin de l'Institut Scientifique, section Sciences de la Terre, 27, 65-8.

Frazier, P. S. \& Page, K. J. (2000). Water Body Detection and Delineation with Landsat TM Data. Photogrammetric Engineering and Remote Sensing, 66(12), 1467-1467.

Ravaioli, M., Langone, L., Miserocchi, S., Focaccia, P., Stanghellini, G., Bortoluzzi, G.. \& Bastianini, M. (2009). The observation system of the Italian coastal zones. In: IEEE Workshop on Environmental, Energy, and Structural Monitoring Systems. http://dx.doi.org/10.1109/EESMS.2009.5341313

Ricchetti, E., Ricchetti,G., \& Sani, R. (2004). Environmental-Geological Study of Coastal Areas of Salento Peninsula (Southern Italy) using Multitemporal Aerial Photography and Satellite Imagery. In: Geoscience and Remote Sensing Symposium.

Sammari, C., Koutitonsky, V. G., \& Moussa, M. (2006). Sea level variability and tidal resonance in the Gulf of Gabes, Tunisia. Continental Shelf Research, 26, 338-350. http://dx.doi.org/10.1016/j.csr.2005.11.006

Shalaby, A., \& Tateishi, R. (2007). Remote sensing and GIS for mapping and monitoring land cover and land-use changes in the Northwestern coastal zone of Egypt. Applied Geography, 27, 28-41. http://dx.doi.org/10.1016/j.apgeog.2006.09.004

Siamo, A., Densham, P. J., \& Haklay, M. M. (2009). Web-based GIS for collaborative planning and public participation: An application to the strategic planning of wind farm sites. Journal of Environmental Management, 90, 2027-2040. http://dx.doi.org/10.1016/j.jenvman.2007.08.032 